\title{
Risks Factors of Caries and Periodontal Diseases in the Patients, after 5 Years Use a Partial Removable Denture
}

\author{
Mantshumba Milolo Augustin1, Duyck Joke², Sekele Isouradi Bourleyi', \\ Lutula Pene Shenda1, Nyimi Bushabu Fidele ${ }^{3,4}{ }^{*}$, Bile Bopili Gabriel ${ }^{5}$, \\ Sofi Ndonga Pierre5, Em. Kalala Kazadi' ${ }^{4}$, Ekofo Inganya Ediz ${ }^{4}$, \\ Kumpanya Ntumba Pierrot ${ }^{1}$, Mayunga Mbuebo', \\ Ntumba Mulumba Kanda ${ }^{1}$, Ignace Naert ${ }^{2}$

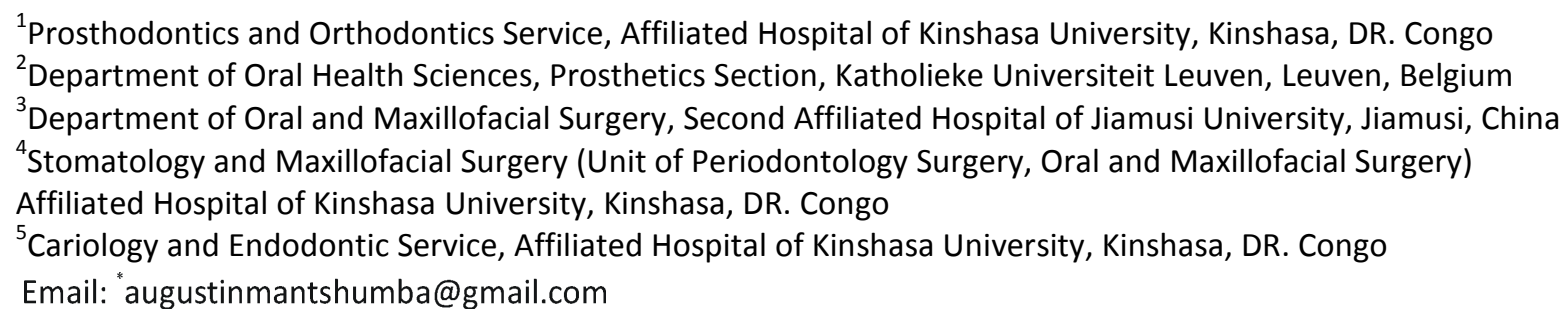

Received 1 August 2016; accepted 26 August 2016; published 29 August 2016

Copyright (C) 2016 by authors and Scientific Research Publishing Inc.

This work is licensed under the Creative Commons Attribution International License (CC BY). http://creativecommons.org/licenses/by/4.0/

(c) (i) Open Access

\section{Abstract}

Objective: The goal of the removable partial denture is to restore impaired esthetics and masticatory function by replacing missing teeth. The aim of this study was to establish a possible correlation between removable partial denture in acrylic resin use after 5 years and dental diseases. Materials and Methods: Partially edentulous patients presenting for removable denture treatment at the Prosthodontics service of the Affiliated Hospital of Kinshasa University, Democratic Republic of Congo were assessed in this study. Patients were randomly assigned into 2 groups: Denture and non-denture group. Caries and periodontal diseases were compared between both groups. Statistical significance was set at $p<0.05$. Results: The average age in the denture and non-denturegroup was $53.15( \pm$ SD 22.05$)$ and $31.59( \pm$ SD 11.98) years. Out of 160 teeth were decayed, both 110 teeth $(68.75 \%)$ in the denture-group and 50 teeth $(31.25 \%)$ in the non-denture group. The DMFT index calculated at start time of the study was 0.2 for both groups, after five years was 7.1 for the denture-group and 2.6 for the non-denture-group. The plaque index in the denture-group had an index of 1 and that of non-denture-group was 0.5. Conclusion: The relationship has been found between patients' wearers a RPD and dental diseases.

\footnotetext{
${ }^{*}$ Corresponding author.

How to cite this paper: Augustin, M.M., Joke, D., Bourleyi, S.I., Shenda, L.P., Fidele, N.B., Gabriel, B.B., Pierre, S.N., Kazadi, Em.K., Ediz, E.I., Pierrot, K.N., Mbuebo, M., Kanda, N.M. and Naert, I. (2016) Risks Factors of Caries and Periodontal Diseases in the Patients, after 5 Years Use a Partial Removable Denture. Open Journal of Stomatology, 6, 185-192.

http://dx.doi.org/10.4236/ojst.2016.68024
} 


\section{Keywords}

\section{Partial Removable Denture Acrylic Resin, Caries and Periodontal Diseases, Oral Health Related Quality of Life}

\section{Introduction}

Contemporary society plays an essential role to promote a good health in the world population, and this action was strengthening as emphasized since 1998 by the world health organization report [1]. Among of the impaired masticatory function and aesthetic causes, the teeth loss have been reported to be one of the cause of impaired masticatory function and aesthetic by many authors [2] [3].

In order to improve the negative consequences of losing teeth, various forms of prosthodontic treatment have been recommended traditionally such as integrity of dental impaired [4] [5]. However, some researchers have been to be challenged in the traditional prosthodontic standard of care, in which all missing teeth should be replaced [3].

In many clinical situations and according to our environment, a partial denture remains again a standard restorative option either because of anatomic defects or because of the patient's psychologically or either because of the financial unable to accept an implant. Thus is also the prime objective of restorative care by many dental practioners in DR. Congo, where a great majority of the dentists provide acrylic removable partial dentures in attempt to restore a complete dental arch [6]. And the Removable partial dentures are commonly used in rehabilitation of edentulous areas, to allow for the implementation of conservative principles and provide a fast and cost-effective treatment. But this Removable partial dentures (RPD) is mechanical structure associated with biological structures and in oral environment, may can carry another situation while its primary objective such as a good hearth. Some research had demonstrated that partial dentures increased the plaque formation and could promote greater occurrence of caries and periodontal disease [7]-[10]. The preliminary study of Sekele et al., during two years showed that the RPD in acrylic resin was harmful for the dental and periodontal health [7]. The RPD is frequently considered to be likewise responsible of the factors that can make problems of carious and /or periodontal lesions and in to increase the mobility of the persistent teeth which entails their loss in the medium or the longer term [11].

Then, it's seems important to estimate the individualized risk and benefit of this prosthesis restoration use in the residual teeth after many years. The aim of this study was to establish the correlation between removable partial denture in acrylic resin use after 5 years and dental diseases.

\section{Materials and Methods}

Prospective interventional study of five hundred and four partially edentulous patients with Kennedy Class I, II, or III edentulous clinically diagnosis and according to classification of Kennedy presented for removable denture treatment at the Prosthodontics service in the Affiliated Hospital of Kinshasa University, DR. Congo between May 2008 to August 2008were assessed in the study. Patients with joint diseases $(n=22)$, hematological diseases $(n=3)$, allergies $(n=19)$, current or history of chemotherapy and radiotherapy $(n=1)$, on a special diet prescribed by a physician ( $\mathrm{n}=17)$, a DPSI equal to or above 2 after oral hygiene instructions $(\mathrm{n}=20)$, carious or infection of endodontic teeth $(n=25)$, and unwilling to participate in the study due to refusal to be without prosthesis when selected to be in the non-denture group $(n=18)$ were excluded (Figure 1$)$. After this applying exclusion criteria and after receiving oral hygiene instructions and providing informed consent, 379 patients (between 19 to 89 years old) were included in the study. They were randomly assigned into 2 groups. One group of patients received a removable acrylic denture (denture group, $n=189$ ) than the other group did not (nondenture group, $n=189$ ). After five years of function, 138 patients were still in the study (60 for the denture group and 78 for the non-denture group). 241 participants lost to follow-up: dropped out because they moved to another town $(n=24)$, because they did not respond to the recall invitation $(n=181)$, because of a changed oral status $(\mathrm{n}=24)$, and due to death $(\mathrm{n}=12)$. In the denture and the non-denture group, 24 and 21 patients had a Kennedy Class I edentulous, 12 and 18 patients had a Kennedy Class II edentulous, and 24 and 39 patients had a Kennedy Class III edentulous respectively. It was after informed consent of patients and obtained an ethical 


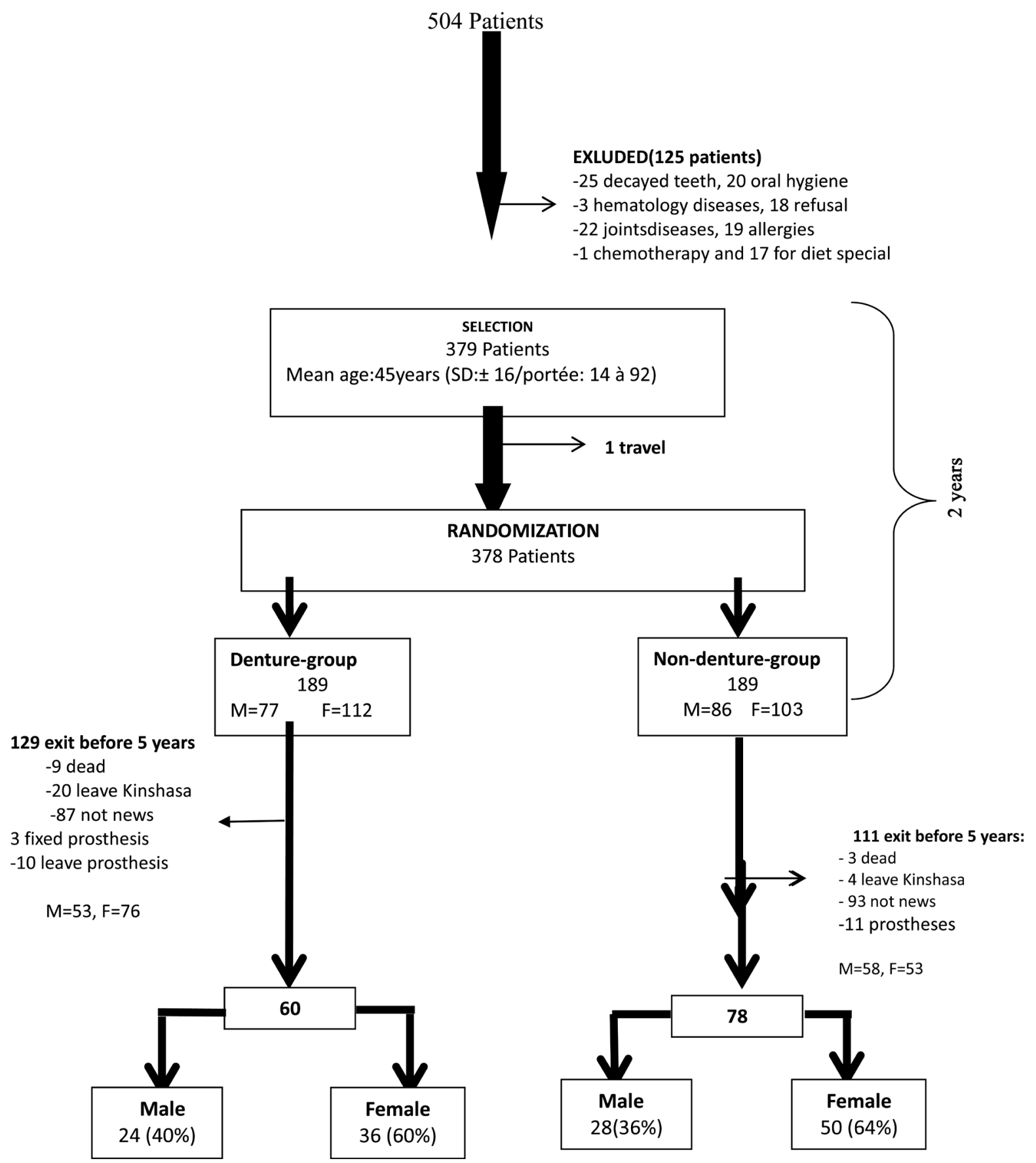

Figure 1. Patients enrolled and randomly in the study + reasons for exclusion and drop out.

committee from the School of health of medicine faculty of Kinshasa University number ESP/CE/018 bis/2009 du 09 Jun 2009 that the study started.

\subsection{Dental Status}

The assessment of the dental status was made by a clinical examination using a dental mirror and probe. The index of DMFT (Decayed-Missing-Filled Teeth), described by Klein et al. [12] was used to assess the dental state of the participants. Score 0: lack of carie, Score 1: Presence of carie, Score 2: Carie obtured, Score 3: Obturation without carie, Score 4: Loss of teeth before prosthodontics restauration, Score 5: Loss of teeth after prosthodon- 
tic restauration and Score 6: Loss of tooth due to the periodontal diseases after prosthodontics restauration.

\subsection{Periodontal Status}

It was assessed using the CPITN (Community Periodontal Index being for Treatment Needs) developed in 1982 [13], who the periodontal pocket $1 \mathrm{~mm}$ to $10 \mathrm{~mm}$, the gingival recession $\geq 2 \mathrm{~mm}$ to $12 \mathrm{~mm}$, the furcation Score 1, 2, and Score 3, the mobility Score1, 2, and Score 3 were reached.

\subsection{Gingival Status}

Gingival index (GI) of Mühlemann Ramfjord was used it to assess the gingival status using a periodontal probe of 1971 [14]. These scores were noted on the 6 zones on these of 16, 21, 24/44, 41 and 36 teeth. Score 0: Heath gingival Score 1: Start gingivitis, Score 2: Chronic gingivitis, Score 3-:Starting periodontics, Score 3+: Periodontics and, Score 4: Evolutive periodontics.

\subsection{Dental Plaque}

Was evaluated using the plaque index (PI) of Orban 1972 [15]. The assessment was done from 8 zones on these following teeth 16, 21, 24, 36, 41 and 44 tooth. Score 0: No plaque, Score 1: Presence of plaque but not in contact with the gingival, Score 2: Presence of vestibular or buccal plaque with gingival Contact, Score 3: Presence of proximal plaque (M or D) with gingival contact. Oral hygiene in terms of plaque index (PI) should be less or equal to 0.6 .

Analysis Statistics: Descriptive statistics (means with standard deviations) treated the main results. The Chi square test were used for some results, to compare or not significant differences between variables. The $\mathrm{P}$ value for rejection of the null hypothesis was $\mathrm{p}<0.05$. ANOVA was used to compare the groups.

\section{Results}

The average age of the participants in the denture and non-denture-group was 53.15 (SD \pm 22.05 ) and 31.59 (SD \pm 11.98 ) years respectively. The majority of the participants were women, namely $60 \%$ and $64 \%$ in the denture and the non-denture group respectively.

Out of 4117 persistent teeth examined in both groups (1857 teeth were for the denture-group and 2260 teeth were for non-denture group), 160 teeth were decayed, both 110 teeth (68.75\%) in the denture-group and 50 teeth (31.25\%) in the non-denture group (Table 1). A significant difference was found between the number of decayed teeth in both groups $(\mathrm{p}=0.00)$. The number of teeth extracted by cause of complications of caries during 5 years was 312 teeth (241 teeth (77.24\%) for the denture-group and 71 teeth (22.76\%) for the non-denture-group (Table 1). The DMFT index calculated at start time of the study was 0.2 for both groups. After five years this index pas to 7.1 for the denture-group and to 2.6 for the non-denture-group.

Regarding the plaque index, our study showed that the participants in the denture-group had an index of 1.3 and that observed in patients in non-denture-group was 0.46 (Table 2) and no statistically significant difference was found in both groups $(\mathrm{p}=0.37)$. The results of the gingival index of patients in the denture-group were 1.3

Table 1. Dental status according to the carie and periodontitis diseases after 5 years of function with a partial denture.

\begin{tabular}{|c|c|c|c|c|}
\hline & $\begin{array}{c}\text { Denture group }(\%) \\
\mathrm{N}=1857 \text { teeth }(45,10)\end{array}$ & $\begin{array}{l}\text { Non denture group (\%), } \\
\mathrm{N}=2260 \text { teeth }(54.90)\end{array}$ & $\mathrm{P}$ value & Total (\%) \\
\hline Decayed teeth & $110(68.75)$ & $50(31.25)$ & 0.00 & 160 \\
\hline Teeth extracted because of Complications of caries & $241(77.24)$ & $71(22.76)$ & 0.00 & 312 \\
\hline Loss teeth because of periodontitis & 35 (61.41) & 22 (38.59) & 0.01 & 57 \\
\hline dental pulp pathology with caries & $63(63)$ & $37(37)$ & 0.00 & 100 \\
\hline obtured teeth no caries & $83(44.86)$ & $102(55.14)$ & 0.04 & 185 \\
\hline no caries; & $1601(43.6)$ & $2071(56.4)$ & 0.00 & 3672 \\
\hline
\end{tabular}


Table 2. Plaque and gingival index between denture and non-denture group.

\begin{tabular}{|c|c|c|c|c|c|c|}
\hline & \multicolumn{2}{|c|}{ Denture group $(\mathrm{n}=60$ ) } & \multicolumn{2}{|c|}{ Non-denture $(\mathrm{n}=78)$} & \multirow{2}{*}{\multicolumn{2}{|c|}{${ }^{*} \mathrm{p}$ value }} \\
\hline & \multicolumn{2}{|c|}{ Mean \pm SD } & \multicolumn{2}{|c|}{ Mean \pm SD } & & \\
\hline & T0 & $\mathrm{T} 5$ & T0 & $\mathrm{T} 5$ & T0 & T5 \\
\hline PI & $0.41 \pm 0.16$ & $1.3 \pm 0.30$ & $0.41 \pm 0.15$ & $0.46 \pm 0.18$ & 0.41 & 0.37 \\
\hline GI & $0.26 \pm 0.13$ & $1.3 \pm 0.38$ & $0.29 \pm 0.11$ & $0.96 \pm 0.30$ & 0.06 & 0.74 \\
\hline
\end{tabular}

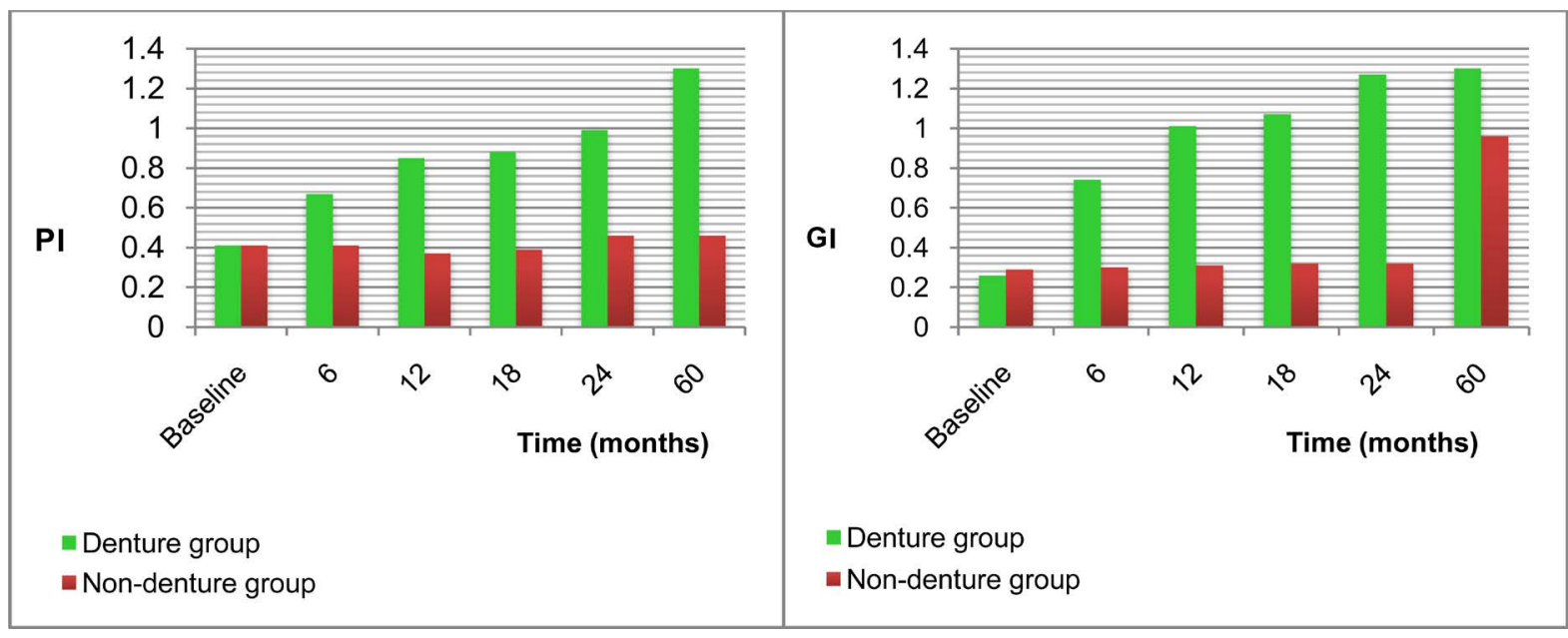

Figure 2. Plaque index (PI), Gingival index (GI) between denture and non-denture group.

and that of the non-denture-group was 0.96 (Table 2). A significant difference was found between the two indexes group $(p=0.00)$.

About evolution of gingival and plaque index in the study time; after 6 months, 12 months, 18 months, 24 months and 60 months compared to the study startup time was constantly increasing in the Denture group than the Non-denture group (Figure 2).

\section{Discussion}

Some studies had reported an increasing risk of caries when wearing RPD. The results of these studies found that, the caries were observed at 6 times more frequently in patients treated with a mandibular RPD compared with patients who received cantilevered bridges, despite the fact that the patients were recalled annually over a 5 year period [16] and adirect relationship between wearing RPD and the prevalence of caries was strong [17]. Our results showed a high incidence of caries in denture group, compared with non-denture group. There is significant risk of developing tooth decay gradually as we advance in time for the denture group. This risk is related to plaque index observed by some studies [7] [8]. Indeed, many of the patients in denture group had increased from RPD with a fairly large plate to ensure retention, to minimize the use of hooks shaped drawn steel; these hooks are themselves harmful to teeth and periodontal by what they are suitable localization plaque retention. Thus, they suggest that the patients' wearers RPD are still a significant risk of caries, more as long as they wear their dentures [8]. The results of this recent study are likewise of the study Budtz-Jorgensen and Fleming observed after two years, 22 carious lesions in 26 patients with RPD compared with 2 carious lesions in 27 patients with joint prostheses extension [16] [18]. The study on the effect of RPD and composition of bacteria after 3 months of insertion in the mouth [19], found that not only oral microbial ecosystem has changed; but also cariogenic bacteria began to put on the tooth surface. They consider the RPD as a potential factor in the development of caries.

From Sekele study, the DMF index at 2 years was 0.3 for the Denture group and 0.2 for Non-denture group [7]; but after 5 years (in recent study) it rose to 7.1 for the Denture group and is 2.6 for the Non-denture group. This increasing trend of DMF index in the Denture group shows that the RPD in acrylic resin is a predisposing factor of carious and periodontal diseases. Both groups lost respectively 241 and 71 teeth that were nevertheless 
treated well before the start of the study. These are the periapical complications of recurrent caries that were the basis for these losses.

\subsection{Gingivitis and Periodontitis}

Local factors such as RPD that can compromise oral hygiene and encourage plaque retention could potentially increase the susceptibility to periodontal disease, particularly at abutment teeth. The periodontal status of 74 RPD wearers for whom no regular recall system was provided was assessed 10 years after insertion of the RPDs [20]. This study identified that the number of remaining teeth had decreased from 606 at baseline to 482 at the10 year follow-up, with a disproportionately higher number of abutment teeth being lost over that time (26.4\%) compared with non-abutment teeth (14.2\%). The authors concluded that there is a high rate of tooth extraction in RPD wearers, and the teeth that were extracted were likely to have been those most severely affected by periodontal disease.

Gingival inflammation, probing depths and gingival recession have all been reported to be greater in patients wearing RPDs [21]. Another study has also reported that wearing RPDs resulted in higher plaque scores, gingival inflammation and loss of attachment at abutment teeth compared with non-abutment teeth, and that there is an increased frequency of higher plaque levels, gingivitis and attachment loss with increased denture age [22]. Tooth mobility has also been reported to increase a greater extent at RPD abutment teeth compared with nonabutment teeth when assessed objectively with the Periotest [20].

In contrast to the above findings, a longitudinal study that followed RPD wearers for 8 - 9 years found that even though oral hygiene of the patients was less than ideal, few teeth were lost and there were no significant differences in caries incidence, changes in probing depths, tooth mobility, or alveolar bone loss between patients who were wearing RPDs and those who were not [23]. Even though there were increased levels of gingival inflammation seen in the locations covered by the RPDs and in the gingival tissues apical to clasp arms, these authors concluded that there was no direct evidence that the RPDs were causing dental or periodontal breakdown.

In another study, the patients with the RPDs had higher mean plaque and gingivitis scores than the patients treated with cantilever bridges, but no changes in probing depths were recorded in either group and only slight decreases in alveolar bone height were revealed. The authors concluded that only minor changes in periodontal status were recorded in the patients treated with cantilever bridges or RPDs [9].

Other studies, using the experimental gingivitis model confirmed that a full coverage lingual plate resulted in more gingival inflammation than a cingulum bar [24].

Indeed, a review on this subject concluded that gingival coverage and a close relationship between parts of the RPD and the gingival tissues increase the risk of complications, and suggested that design of RPDs should focus on open/hygienic design principles rather than biomechanical considerations.

In our results, the plaque index was significantly higher in the Denture group. The plaque scores after five years by contributing to those starting study was 0.41 (SD: \pm 0.16$)$ and 0.46 (SD: \pm 0.15$)(\mathrm{p}<0.05)$ and 1.3 (SD \pm $0.30)$ and 0.46 (SD \pm 0.18 ) respectively for the Denture group and the Non-denture group. These results were similar to study of Isa and Yusof that indicated a high frequency of plaque index for the teeth in contact with the RPD and the teeth of the non-paired antagonists arcades. This study agrees that oral hygiene in the Denture group was not optimal despite repetitions of hygiene at each control instructions. Also, our results showed that the wearing RPD in acrylic resin has a negative influence on the periodontal. The gingival index after 6 months, 12 months, 18 months, 24 months and 60 months compared to the study startup time is constantly increasing in the Denture group compared to the Non-denture group (Figure 2). The average gingival index recorded after five years in each group was 1.27 (SD: \pm 0.38 ) for Denture group and 0.96 (SD: \pm 0.30 ) for the Non-denture group. The normal gingival index (Klein $\mathrm{H}$ et al. 1940) is $\leq 0.3$. The difference is highly statistically significant $(\mathrm{p}<0.05)$. This shows that the Denture group presents their gums inflammation, similar to others studies [22] [23] that reported a high frequency of periodontal infection in RPD wearers and gingival index significantly increased with age of the prosthesis, and also that noted a high frequency of gingival inflammation $(\mathrm{p}<0.05)$ in the regions covered by the RPD compared to regions not covered and they attribute this to poor oral hygiene.

\subsection{Limit of Study}

- Hoppe to have a large final sample and from different regions of DR. Congo than use in this study

- The changes of address and telephone number, and a few deaths cases were among the limitation of this re- 
search

- Recall and travel patients for checkup each 6 months

\section{Conclusion}

The relationship has been found between patients' wearers a RPD and dental diseases at 6 months wearing a RPD. The gingival and the plaque index are continually raised after each 6 months until 60 months in Denture group compared to the Non-denture group, thus increase the risks of caries and periodontal diseases. All patients who wear RPDs should be enrolled into a regular recall of each 3 months and maintain this programm in order to minimize somewhat the risk of dental diseases.

\section{Competing Interests}

Authors have declared that no competing interests exist.

\section{References}

[1] World Health Organisation (1992) Recent Advances in Oral Health. WHO Technical Report, Series N 826. WHO Series, Geneva.

[2] Tsuga, K., Carlsson, G.E., Osterberg, T. and Karlsson, S. (1998) Self-Assessed Masticatory Ability in Relation to Maximal Bite Force and Dental State in 80-Year-Old Subjects. Journal of Oral Rehabilitation, 25, 117-124. http://dx.doi.org/10.1046/j.1365-2842.1998.00233.x

[3] Witter, D.J., Cramwinckel, A.B., van Rossoum, G.M.J.M. and Kayser, A.F. (1990) Shortened Dental Arches Masticatory Ability. Journal of Dentistry, 18, 185-189. http://dx.doi.org/10.1016/0300-5712(90)90107-P

[4] Kanno, T. and Carlsson, G.E. (2006) A Review of the Shortened Dental Arch Concept Focusing on the Work by the Kayser /Nijmegen Group. Journal of Oral Rehabilitation, 33, 850-862. http://dx.doi.org/10.1111/j.1365-2842.2006.01625.x

[5] Sheiham, A. and Steele, J. (2001) Does the Condition of the Mouth and Teeth Affect the Ability to Eat Certain Foods, Nutrient and Dvetary Intake and Nutritional Status amongst Older People? Public Health Nutrition, 4, 797-803. http://dx.doi.org/10.1079/PHN2000116

[6] Kupampanya, M.M, Sekele, I.B., Mayunga, M., Lutula, P.S. and Ntumba, M.K. (2015) Syndrome ectodemique de Cap de Pont et rehabilitation orale prothétique. A propos d'un cas Clinique. Odsto, 38, 43-45.

[7] Sekele, I.B. (2016) influence de la Prothèse amovible Partielle en résine acrylique sur la santé bucco-dentaire et la qualité de vie. Odonto-Stomatologie Tropicale, 39, 36-45.

[8] Jepson, N.J.A., Moynihan, P.J., Kelly, P.J., Watson, G.W. and Thomason, J.M. (2001) Caries Incidence Following Restoration of Shortened Lower Dental Arches in a Randomized Controlled Trial. British Dental Journal, 191, 140144.

[9] Isidor, F. and Budtz-Jørgensen, E. (1990) Periodontal Conditions Following Treatment with Distally Extending Cantilever Bridges or Removable Partial Dentures in Elderly Patients. A 5-Year Study. Journal of Periodontology, 61, 21-26.

[10] Bergman, B. and Ericson, G. (1986) Cross-Sectional Study of Patients Treated with Removable Partial Dentures with Special Reference to the Caries Situation. Scandinavian Journal of Dental Research, 94, 436-442. http://dx.doi.org/10.1111/j.1600-0722.1986.tb01784.x

[11] Vanzeveren, C., D’hoore, W., Bercy, P. and Leloup, G. (2003) Treatment with Removable Partial Dentures: A Longitudinal Study. Part II. Journal of Oral Rehabilitation, 30, 459-469. http://dx.doi.org/10.1046/j.1365-2842.2003.01107.x

[12] Klein, H., Palmer, C.E. and Knutson, J.W. (1940) Studies on Dental Caries: A Procedure for Recording and Statistical Proceeding of Dental Examinations Findings. Journal Dentistry Restorative, 19, 243-252. http://dx.doi.org/10.1177/00220345400190030401

[13] Ainamo, J., Barmes, D., Beagrie, G., Cutress, T., Martin, J. and Sardo-Infirri, J. (1982) Development of the World Health Organization (WHO) Community Periodontal Index of Treatment Needs (CPITN). International Dental Journal, 32, 281-291.

[14] Mühlemann, H.R. and Son, S. (1971) Gingival Sulcus Bleeding-A Leading Symptom in Initial Gingivitis. Helvetica Odontologica Acta, 15, 107-113.

[15] Orban (1972) Gemodificeerde Navy Plaque Index. Parodontale Indices II. 8. 
[16] Budtz-Jorgensen, E. and Fleming, I. (1990) A Five Years Longitudinal Study of Cantilevered Fixed Partial Dentures Compared with Removable Partial Dentures in a Geriatric Population. The Journal of Prosthetic Dentistry, 64, 42-47. http://dx.doi.org/10.1016/0022-3913(90)90151-2

[17] Nevalainen, M.J., Närhi, T.O. and Ainamo, A. (2004) A 5-Year Follow-Up Study on the Rehabilitation of the Elderly in Helsinki, Finland. Journal of Oral Rehabilitation, 31, 646-652.

[18] Budtz-Jorgensen, E. and Fleming, I. (1987) Cantilever Bridges or Removable Partial Dentures in Geriatric Patients: A Two-Year Study. Journal of Oral Rehabilitation, 14, 239-249. http://dx.doi.org/10.1111/j.1365-2842.1987.tb00715.X

[19] Gao, N., Su, B., Hu, Y., Xiao, X., Zhu, Z. and Liu, Y. (1998) The Effect of Removable Partial Denture on the Composition of Bacteria on the Apt-to-Decay Site of Abutment Teeth. Hua Xi Yi Ke Da Xue Xue Bao, 29, 33-37.

[20] Kern, M. and Wagner, B. (2001) Periodontal Findings in Patients 10 Years after Insertion of Removable Partial Dentures. Journal of Oral Rehabilitation, 28, 991-997. http://dx.doi.org/10.1046/j.1365-2842.2001.00788.x

[21] Rissin, L., et al. (1985) Six-Year Report of the Periodontal Health of Fixed and Removable Partial Denture Abutment Teeth. Journal of Prosthetic Dentistry, 54, 461-467. http://dx.doi.org/10.1016/0022-3913(85)90413-5

[22] Yusof, Z. and Isa, Z. (1994) Periodontal Status of Teeth in Contact with Denture in Removable Partial Denture Wearers. Journal of Oral Rehabilitation, 21, 77-86. http://dx.doi.org/10.1111/j.1365-2842.1994.tb01126.x

[23] Chandler, J.A. and Brudvik, J.S. (1984) Clinical Evaluation of Patients Eight to Nine Years after Placement of Removable Partial Dentures. Journal of Prosthetic Dentistry, 51, 736-743. http://dx.doi.org/10.1016/0022-3913(84)90366-4

[24] Budtz-Jörgensen, E. (1996) Restoration of the Partially Edentulous Mouth a Comparison of Overdentures, Removable Partial Dentures, Fixed Partial Dentures and Implant Treatment. Journal of Dentistry, 24, 237-244. http://dx.doi.org/10.1016/0300-5712(95)00075-5

\section{Submit or recommend next manuscript to SCIRP and we will provide best service for you:}

Accepting pre-submission inquiries through Email, Facebook, LinkedIn, Twitter, etc. A wide selection of journals (inclusive of 9 subjects, more than 200 journals)

Providing 24-hour high-quality service

User-friendly online submission system

Fair and swift peer-review system

Efficient typesetting and proofreading procedure

Display of the result of downloads and visits, as well as the number of cited articles

Maximum dissemination of your research work

Submit your manuscript at: http://papersubmission.scirp.org/ 